\title{
Investigating the bunkering choice determinants: the case of the port of Antwerp
}

\author{
Raimonds Aronietis ${ }^{1 *}$ (D) Christa Sys ${ }^{2}$, Edwin van Hassel $^{2}$ and Thierry Vanelslander ${ }^{2}$
}

\author{
* Correspondence: \\ raimonds.aronietis@itf-oecd.org \\ ${ }^{1}$ International Transport Forum at \\ the OECD, 2 rue André Pascal, \\ F-75775 Paris, France \\ Full list of author information is \\ available at the end of the article
}

\begin{abstract}
From a European, regional and local perspective, as well as from the perspective of port authorities, it is important that waterborne transport becomes sustainable. As possible solutions to comply with new types of legislation (SECA-zones), shipping companies consider amongst others the use of liquefied natural gas (LNG) and low sulphur fuel. An important aspect in the choice of fuel are the current bunker strategies of the shipping companies.

Therefore, this research deals with the bunker market and wants to increase the insight into the strategy of the shipping companies, why they bunker in Antwerp or in another port (e.g. Rotterdam). Which criteria are the most important: the price per tonne, the quality of the fuel, or another characteristic (e.g. calling pattern)?

The research question is answered with a discrete choice experiment, evaluating the preferences of the shipping lines. A multinomial logit model is chosen for this experiment because of the low expected number of respondents. The research is further expanded with more in-depth interviews with bunkering decision makers of various shipping companies.
\end{abstract}

\section{Introduction}

From a European, regional and local perspective, as well as from the point of view of port authorities, it is important that waterborne transport becomes sustainable. Liquefied natural gas (LNG) is one of the options seen as an alternative fuel for deepsea, shortsea and inland navigation ships. A number of port authorities expressed the ambition to facilitate the introduction of LNG as a shipping fuel, all the more, given that in Sulphur Emission Control Areas (SECAs) from 2015 onwards, more stringent standards apply to the sulphur emissions from ships (Sys et al. 2015). Regulations reducing the sulphur emissions from shipping are also expected at a global level from 2020 onwards (Aronietis et al. 2016).

If ship owners want to use LNG, then the ports must facilitate the LNG bunker infrastructure. Before a port authority can invest in this infrastructure, it is foremost important to have an idea of the potential demand from deepsea, shortsea and inland navigation carriers to bunker LNG instead of Heavy Fuel Oil (HFO) and/or Marine Gas Oil (MGO). This paper develops a generic forecasting method at port level. This method is then applied to the port of Antwerp. The potential demand of LNG as a fuel

(c) The Author(s). 2017 Open Access This article is distributed under the terms of the Creative Commons Attribution 4.0 International License (http://creativecommons.org/licenses/by/4.0/), which permits unrestricted use, distribution, and reproduction in any medium, provided you give appropriate credit to the original author(s) and the source, provide a link to the Creative Commons license, and indicate if changes were made. 
can be the foundation for strategic longer-term planning and project development with regards to LNG as a fuel (Aronietis et al. 2016).

An important aspect in the choice for the use of LNG or low-sulphur fuel are the current day bunker strategies of the shipping companies.

Previous research (Aronietis et al. 2016) dealt with the potential of LNG as a shipping fuel for the port of Antwerp. During this research, several interviews were done with stakeholders to get more insights in the potential usage of LNG as a bunker fuel. Form those interviews, it became known that issues like quality of delivery, speed of delivery, available fuel options (whether it is LNG, MGO or HFO), etc. are important. Hence, there appear to be multiple influencing criteria. It is important to discern which are the key decision criteria for a shipping company when deciding on its bunkering strategy.

This research deals with the bunker market and wants to increase the insight into the strategy of the shipping companies in the current bunker market. It is the aim of this research to determine which criteria are the most important in determining the bunker strategy: the price per tonne, the quality of the fuel, or another criterion (e.g. calling pattern).

In order to answer the research question, first, a literature review was performed. Based on that, a two-stage methodology was applied. Firstly, a discrete choice experiment was set up, evaluating the preferences of the shipping lines, where a multinomial logit model is chosen for this experiment because of the low expected number of respondents. Secondly, also qualitative research through interviews was performed to better understand the bunkering choice strategies.

The remainder of the paper is structured as follows. First, a literature review is given which deals with the bunkering choice determinants. Secondly, the methodology is explained. Thirdly, the used data will be described. This is followed by the results of the discrete choice experiment and the interviews. The paper is finalized with conclusions.

\section{Literature}

In previous research, much interest went into the optimization for liner shipping of the bunkering port in combination to the sailing speed and the fixed sailing route of the vessel.

In Yao et al. (2012), a bunker fuel management strategy is studied for a single shipping liner service. The research includes bunkering port selection (where to bunker), bunkering amounts and ship speed adjustment. The main reason to take all these elements into account is that these three components are interrelated. In the research, a theoretical model is developed on which an optimization of the three above-mentioned parameters is performed. The optimization in their research is done based on the fuel cost and does not take into account which parameters might affect the decision to bunker at a certain port.

Ghosh et al. (2015) study the bunkering service contracts of liner shipping companies and determine the liners' optimal bunkering strategy. The authors argue that typically, liner operators enter into a contract with fuel suppliers where the contract is specified by a fixed fuel price and amount, to mitigate the fluctuating spot prices and uncertain fuel consumption between the ports. They propose a dynamic 
programming model to optimize the total bunkering cost when both fuel consumption and fuel prices are uncertain. From the preformed numerical experiments, it is determined that the most important parameters to take into account in the decision making process are the contract amount of bunker fuel, the contract price and the damage charge multiplier.

Also Wang et al. (2014) analysed the bunkering strategy for the liner shipping industry. In their research, a benchmarking framework was developed that evaluates bunkering ports' performances in regular liner routes in order to choose optimal ones. The authors argue that bunkering port selection is typically a multi-criteria group decision problem, and in many practical situations, decision makers cannot form proper judgments using incomplete and uncertain information in an environment with exact and crisp values. Therefore, a fuzzy numbers approach was proposed in their research. In the developed benchmark, key performance factors (KPFs) of bunkering ports are identified. The highest ranking parameters, out of 15, are: bunker price, bunker quality, and safety of the bunkering. These bunker performance factors where obtained via a questionnaire with decision makers from selected liner shipping companies. Secondly, the authors applied the developed framework to a case study for a container loop between China, Korea and Japan.

Acosta et al. (2011) explored the factors affecting bunkering competitiveness of the ports of Gibraltar, Ceuta and Algeciras. Also in this study, the authors used interviews and questionnaires targeted to the institutions and firms involved in port activities at

Table 1 Factors affecting bunkering competitiveness

\begin{tabular}{|c|c|c|c|}
\hline Order & Factors & Variable & Mean (-) \\
\hline 1 & Fuel price & V1 & 4.76 \\
\hline 2 & Geographical advantage & V14 & 4.59 \\
\hline 3 & Anchoring and docking availability & V10 & 4.39 \\
\hline 4 & Simplicity of accessibility to port & V8 & 4.15 \\
\hline 5 & Port tariffs & V2 & 4.03 \\
\hline 6 & Supply waiting time & V5 & 4.02 \\
\hline 7 & Provision of services, port congestion & V9 & 4 \\
\hline 8 & Fuel quality & V7 & 3.95 \\
\hline 9 & Port access waiting time & V6 & 3.78 \\
\hline 10 & Ship inspection thoroughness & V19 & 3.78 \\
\hline 11 & $\begin{array}{l}\text { Prices of complementary services for fuel supply at berth } \\
\text { (pilotage, mooring, etc.) }\end{array}$ & V3 & 3.76 \\
\hline 12 & Simplicity of crew changes & V12 & 3.71 \\
\hline 13 & Presence of restrictive environmental regulations & V18 & 3.71 \\
\hline 14 & Customs strictness & V20 & 3.7 \\
\hline 15 & Clear and precise information about services & V13 & 3.58 \\
\hline 16 & $\begin{array}{l}\text { Hinterland proximity (proximity of goods to } \\
\text { destination/origin centres) }\end{array}$ & V15 & 3.56 \\
\hline 17 & Port security & V17 & 3.49 \\
\hline 18 & $\begin{array}{l}\text { Prices of complementary services for fuel supply } \\
\text { at anchorage }\end{array}$ & V4 & 3.46 \\
\hline 19 & Organizational tradition and capacity & V11 & 3.46 \\
\hline 20 & Industrial disputes & V16 & 3.44 \\
\hline
\end{tabular}

Source: Acosta et al. (2011) 
the ports of the Strait of Gibraltar. During the interviews, the interviewees were asked whether they agreed if a proposed factor was important. In that study, the authors focused on the supply side of the bunkering market (fuel providers and bunkering companies). In Table 1, an overview of the 20 investigated bunker factors and their results is given.

From their analysis, it was determined that from the bunker supply point of view, the fuel prices, together with geographical advantage, are the most important factors. Port operators attach less importance to other factors such as industrial disputes and port security.

The results of their study have indicated some important policy implications for improving port competitiveness. The authors express that besides price competition, also other opportunities to improve competitiveness, such as docking improvements, port access, port tariffs and waiting time can be aimed at.

Based on the literature review regarding the bunker strategies, it can be concluded that most research focused on the container liner industry. Only in the research of Acosta et al. (2011), multiple shipping companies were integrated in the study, but these authors focused on supply side of the bunkering operations. In Acosta et al. (2011) and Wang et al. (2014), interviews were held to obtain information, but these studies focused on either the southern part of Spain or the Eastern Asian regions. Also the above-mentioned papers did not quantify the importance of the different bunker factors.

In our research, we focus on the bunkering determinants for all shipping segments (not only container liners) and with a special focus on the port of Antwerp. We also focus on the demand side and not on the supply side of the bunker decisions. Finally, the importance of the different bunker factors is quantified.

\section{Methodology}

In this paper, a two-stage methodology of both qualitative research through interviews and a discrete choice experiment was chosen. The reason to use both approaches is that in order to do the discrete choice experiment, interviews had to be done. By including also an in-depth interview, it was possible to obtain richer and more nuanced results. Both methods are targeting at the evaluation of the preferences of the shipping lines (demand side) on the bunkering decisions.

The in-depth interviews with bunkering decision makers were done:

- To obtain the main bunkering rationale and strategy.

- To present a discrete choice experiment to the interviewees to also obtain quantitative results.

The discrete choice experiment is designed keeping in mind the potentially small number of respondents that were to be interviewed, because the number of people in the shipping companies directly involved in making bunkering choices is limited. It also has the advantage of being easy for the respondents to answer by presenting them with a situation that mimics the bunkering choices that they make on daily basis. It does not ask them to rank or rate separate attributes. The approach is flexible enough for the interviews to be conducted either in person, or over the phone. 


\section{Interview methodology}

In this section, the methodology of the in-depth interviews with the shipping companies is described and explained. The shipping companies that are calling at the port of Antwerp and have offices in Antwerp are selected as respondents for the interviews and the discrete choice experiment. The target was to interview the most important shipping companies calling at the port of Antwerp and to speak to the people who are directly involved in making the bunkering choice in the company.

From first contacts with the shipping lines in Antwerp, it became clear that the decisions with respect to bunkering are taken at the main offices of the companies. Therefore, the local offices in Antwerp were used as entry points to gain access to the relevant people.

During the interviews with the shipping companies, a range of relevant topics were addressed through a semi-structured interview. The developed questionnaire was used as a guideline during the interview.

\section{Discrete choice methodology}

Based on the data presented in Acosta et al. (2011), factors of port competitiveness (see Table 1) are regrouped for use in the discrete choice experiment. The regrouping can be seen in Table 2. The first-level grouping of the factors is used as attributes in the discrete choice experiment, but the second level shows the ranking of the factors amongst themselves by importance based on Acosta et al. (2011).

We have opted for a multinomial logit model for this experiment because of the low expected number of respondents. A Bayesian approach is used to make the experiment

Table 2 Factors grouped by type

\begin{tabular}{ll}
\hline 1st level & 2nd level \\
\hline PRICE & Fuel price \\
PROP_F & Fuel quality \\
COST_OTH & Port tariffs \\
& Prices of complementary services for fuel supply \\
& at berth (pilotage, mooring, etc.) \\
& Prices of complementary services for fuel \\
& supply at anchorage \\
& Geographical advantage \\
GEO & Accessibility to port (from sea side) \\
& Hinterland proximity \\
& Anchoring and docking availability \\
P_CONGESTION & Supply waiting time \\
& Provision of services, port congestion \\
& Port access waiting time \\
PROP_P & Ship inspection thoroughness \\
& Simplicity of crew changes \\
& Presence of restrictive environmental regulations \\
& Customs strictness \\
& Clear and precise information about services \\
& Port security \\
Organizational tradition and capacity & Industrial disputes \\
&
\end{tabular}


less depending on the number of respondents. Based on Acosta et al. (2011), we have come to the attributes of Table 3, including their corresponding levels.

The design of the discrete choice experiment starts with previously described attributes. Prior to generating the design of the experiment, here, information from the study of Acosta et al. (2011) is integrated. The design benefits from the information regarding prior mean and variance values. The design of the experiment is generated to produce the choice profiles that are used during the interviews with the shipping companies.

Because previous experimental data is available from Acosta et al. (2011), the prior mean values are estimated based on the results of this research, see Table 4. The values in column "Estimated prior mean" are calculated by multiplying the average valuation by 2 and dividing by 10 . This is done to produce initial estimated mean values for design generation between 0 and 1 that incorporate the valuation of the attributes from Acosta et al. (2011).

The design generation was done keeping in mind that there is a chance that some of the approached shipping lines would not be willing to respond to the questionnaire. Therefore, the designs of the survey are based on the characteristics shown in Table 2. Each shipping line was presented with a different discrete choice survey, which contains 12 questions.

A design with two alternatives and a relatively small number of questions is chosen to keep it simple for the respondents. This design approach, according to conclusions by Bech et al. (2011), should also avoid the cognitive burden of the respondents.

In order to achieve the best possible questionnaire, JMP software ${ }^{1}$ allows generating numerous designs and choosing the best one. To benefit from this approach, 1000 random starting designs were run and the best one was chosen within the software.

An example of a choice set that respondents are presented with is shown in Fig. 1. The respondent is asked to choose the port, which he considers best for bunkering, and to tick the corresponding answer ring.

The choices of the respondents in a discrete choice experiment are assumed to be determined by the respondents' trade-offs between the attributes. From the available

Table 3 Attribute levels ${ }^{a}$

\begin{tabular}{|c|c|c|c|c|c|}
\hline Attribute & Attribute description & Attribute levels & & & \\
\hline PRICE & Price, USD/t & 650 & 625 & 600 & 575 \\
\hline PROP_F & $\begin{array}{l}\text { Quality of fuel provision: } \\
\text { trust that correct } \\
\text { quantities and quality } \\
\text { bunkered }\end{array}$ & no & yes & & \\
\hline COST_OTH & $\begin{array}{l}\text { Other costs related to } \\
\text { calling port }\end{array}$ & $+20 \%$ & $+10 \%$ & 0 & $-10 \%-20 \%$ \\
\hline GEO & $\begin{array}{l}\text { Market fit with the } \\
\text { location of the port }\end{array}$ & $\begin{array}{l}\text { Bad: small market, } \\
\text { far ( } 3 \text { or more days) } \\
\text { from O/D of goods }\end{array}$ & $\begin{array}{l}\text { Average: medium-sized } \\
\text { market, or further } \\
\text { (1-2 days) from O/D } \\
\text { of cargo }\end{array}$ & $\begin{array}{l}\text { Good } \\
\text { mark } \\
1 / 2 \text { da) }\end{array}$ & $\begin{array}{l}\text { where the } \\
\text { t is, less than } \\
\text { by truck }\end{array}$ \\
\hline P_CONGESTION & Port congestion & High & Medium & Low & \\
\hline PROP_P & $\begin{array}{l}\text { Administrative } \\
\text { attractiveness of the port }\end{array}$ & Low & Medium & High & \\
\hline
\end{tabular}

Source: Own composition

athe most likely preferred attribute levels appear last 
Table 4 Estimated prior mean values

\begin{tabular}{lll}
\hline Attribute & Average valuation $^{\text {a }}$ & Estimated prior mean \\
\hline PRICE & 4.76 & 0.952 \\
PROP_F & 3.95 & 0.79 \\
COST_OTH & 3.75 & 0.75 \\
GEO & 4.1 & 0.82 \\
P_CONGESTION & 4.0475 & 0.8095 \\
PROP_P & 3.60875 & 0.72175 \\
\hline
\end{tabular}

afrom Acosta et al. (2011)

choices, a respondent would always choose the alternative that maximises his utility. A utility function for bunkering can therefore be defined:

$$
\mathrm{U}_{\mathrm{i}}=\mathrm{U}_{\text {PRICE }}+\mathrm{U}_{\text {PROP_F }}+\mathrm{U}_{\text {COST_OTH }}+\mathrm{U}_{\mathrm{GEO}}+\mathrm{U}_{\text {P_CONGESTION }}+\mathrm{U}_{\text {PROP_P }}+\varepsilon
$$

Where:

$U_{i}$ is the utility of the alternative $i$,

$\mathrm{U}_{\text {PRICE }}$ is the utility of price for alternative $\mathrm{i}$,

$\mathrm{U}_{\text {PROP_F }}$ is the utility of quality of fuel provision for alternative $i$,

$\mathrm{U}_{\text {COST_OTH }}$ is the utility of other costs related to calling at a port for alternative $i$,

$\mathrm{U}_{\mathrm{GEO}}$ is the utility of market fit with the location of the port for alternative $\mathrm{i}$,

$U_{\text {P_CONGESTION }}$ is the utility of port congestion for alternative $i$,

$\mathrm{U}_{\text {PROP_P }}$ is the utility of administrative attractiveness of the port for alternative $i$, $\varepsilon$ is the error term.

According to McFadden (1974), in the multinomial logit model, the relative utility of an alternative in a choice situation can be described as:

\section{Choice Set: 1}

If you must choose between the two ports on your route, would you prefer to bunker fuel at port A or port B?

\begin{tabular}{|c|c|c|}
\hline Fuel price, USD/t & $\begin{array}{l}\text { Port A } \\
600\end{array}$ & $\begin{array}{l}\text { Port B } \\
\text { S50 }\end{array}$ \\
\hline $\begin{array}{l}\text { Quality of fuel provision: trust } \\
\text { that correct quantities and } \\
\text { quality bunkered }\end{array}$ & No & Yes \\
\hline $\begin{array}{l}\text { Other costs related to calling port } \\
\text { (+ or - } \% \text { compared to global average) }\end{array}$ & $-10 \%$ & $+20 \%$ \\
\hline $\begin{array}{l}\text { Market fit with the location of } \\
\text { the port }\end{array}$ & $\begin{array}{l}\text { Good: where the market is, } \\
\text { less than } 1 / 2 \text { day by truck }\end{array}$ & $\begin{array}{l}\text { Bad: small market, far ( } 3 \text { or } \\
\text { more days) from } \\
\text { origin/destination of goods }\end{array}$ \\
\hline Port congestion (sea side) & Medium & High \\
\hline $\begin{array}{l}\text { Administrative } \\
\text { attractiveness of the port }\end{array}$ & i & Medium \\
\hline
\end{tabular}

Fig. 1 Questionnaire for the discrete choice experiment. Source: own composition 


$$
\mathrm{U}_{\mathrm{jsn}}=\mathrm{x}_{\mathrm{jsn}}^{\prime} \beta+\varepsilon_{\mathrm{jsn}}
$$

- $\mathrm{U}_{\mathrm{jsn}}$ is the utility that a respondent $\mathrm{n}$ attaches to alternative $\mathrm{j}$ in choice situation $\mathrm{s}$,

- $\mathrm{x}_{\mathrm{j} \text { sn }}^{\prime}$ is $\mathrm{k} \times 1$ vector containing the attribute levels of alternative $\mathrm{j}$ in choice set $\mathrm{s}$ for respondent $\mathrm{n}$,

- $\beta$ is $\mathrm{k} \times 1$ vector of parameter values (part-worths),

- $\varepsilon_{\text {jsn }}$ is the independent and identically distributed Gumbel error term, which incorporates the unobserved sources of utility.

Given the random utility model, the multinomial logit probability that respondent $\mathrm{n}$ chooses profile $\mathrm{j}$ in choice set $\mathrm{s}$ is ${ }^{2}$ :

$$
\operatorname{Prob}_{\mathrm{jsn}}=\frac{\exp \left(\mathrm{x}_{\mathrm{jsn}}^{\prime} \beta\right)}{\sum_{\mathrm{t}=1}^{\mathrm{j}} \exp \left(\mathrm{x}_{\mathrm{tsn}}^{\prime} \beta\right)}
$$

For the bunkering choice experiment, the following multinomial logit model is constructed. It includes all the attributes that are included in the discrete choice experiment.

$$
\begin{aligned}
\mathrm{U}= & \beta_{1} \text { PRICE } 1+\beta_{2} \text { PRICE } 2+\beta_{3} \text { PRICE } 3+\beta_{4} \text { PRICE } 4+\beta_{5} \text { PROP }_{\mathrm{F}}+ \\
& +\beta_{6} \text { COST_OTH } 1+\beta_{7} \text { COST_OTH } 2+\beta_{8} \text { COST_OTH3 }+\beta_{9} \text { COST_OTH4 }+ \\
& +\beta_{10} \text { GEO } 1+\beta_{11} \text { GEO } 2+\beta_{12} \text { CONGESTION } 1+\beta_{13} \text { CONGESTION } 2+ \\
& +\beta_{14} \text { PROP }_{\mathrm{P} 1}+\beta_{15} \text { PROP }_{\mathrm{P} 2}+\varepsilon
\end{aligned}
$$

This utility function is the basis of the multinomial logit model to be estimated based on the responses of the shipping companies.

\section{Antwerp case: contributing companies}

In this section, the contributing shipping companies to the interviews and discrete choice survey are described. The shipping companies that are calling at the port of Antwerp and have offices in Antwerp are selected as respondents for the survey.

The discrete choice experiments could be arranged with five shipping companies, shown in Table 5. The experiments were conducted by going to the offices of the company, or by phone.

The discrete choice experiment could not be done with four other shipping companies (Fednav, Grimaldi, Hamburg Süd and Maersk Line), who were only willing to give qualitative answers, because they did not consider the questionnaire relevant to their business model. They explained that their choice is not made by taking in consideration all the attributes that appeared in the questionnaire, because some of those are fixed for them as the decision maker. Therefore they do not consider answering an "honest" thing to do.

\section{Results}

In this section, the qualitative results of the interviews with the shipping companies are described, even as the outputs of the discrete choice experiment. 
Table 5 Overview of contributing companies

\begin{tabular}{llll}
\hline & Company & Interviewee & Discrete choice \\
\hline 1 & Clipper & Senior Bunkers Manager & $\times$ \\
2 & Exmar & Deputy Chartering Director & $\times$ \\
4 & Fednav & Manager Bunker Services & \\
5 & Grimaldi & Bunker Department Manager & \\
6 & Hambug Süd & Bunker Management & \\
7 & MSC & Chief executive officer & $\times$ \\
8 & TransAtlantic & Line Manager & $\times$ \\
9 & Wallenius Wilhelmsen & COO Ocean Operations & \\
\hline
\end{tabular}

Source: own compilation

\section{Qualitative results}

First of all, company-specific open questions are asked, about how the bunkering is dealt with within the respondent's company. It is asked who the decision maker is and how they deal with the bunkering decisions. In the form of open questions, it is also asked what the shipping company considers when the bunkering decision is made in favour of a certain port. The responses to these questions give a perception on what is considered when those choices are made.

Bunkering decisions in practice are usually taken by a department that deals with bunkering, which is always located in the head office of the shipping company. The decision makers are the bunker managers, who deal only with bunkering of the ships.

Based on the interviews with the shipping companies, the logic of the bunkering choice is the following:

- Bunkering can only be done at the ports of call.

- Bunkering is only done with the companies that are trusted (fuel flow meters are installed or a bunker surveyor is used).

- The best price amongst the ports of call is looked for (price including fuel price + taxes + transport cost)

- Certain negotiation techniques are employed to get the best price in the chosen port (e.g. getting several quotes and asking the second cheapest to beat the cheapest, saying that the ship will go to Rotterdam afterwards and asking for a better price);

- The bunkering is then done so that no extra time is wasted for it, so during the loading/unloading operations.

In relation to the factors that a shipping company considers for bunkering, the respondents are unanimous in their comments. It is always the price and quality of fuel provision (trust that the correct quantity and quality is supplied) that are considered when the choice is made. The price is said to include also other costs that are specifically related to bunkering, or if a port is called at specifically for bunkering, then the related costs are considered as well.

It must be mentioned that calling at a port specifically for bunkering is not a practice that shipping companies undertake regularly, but sometimes the routing of the ship or 
the price may make the shipping company consider it. This might be the case when certain fuel types, such as low-sulphur fuels, are not available, or they might calling at the port of Gibraltar purely for bunkering.

The above-described bunkering process is graphically depicted in Fig. 2. In this figure, it is shown that the bunker decision is made by the vessel's headquarters and a few port of calls in advance. In each port that the vessel will call at, several bunker providers will be contacted. The bunker providers that are not trusted will not be taken into consideration ("wiped-out bunker provider"). Ports that are not on the scheduled route of the vessel are in general not taken into account. Based on the different quotes the headquarters receive $\left(\mathrm{B} . \mathrm{O}_{1, \mathrm{C}}, \mathrm{B} . \mathrm{O}_{3, \mathrm{~A}}, \mathrm{~B} . \mathrm{O}_{3, \mathrm{C}}\right)$, the department responsible for bunkering will take the offer with the lowest cost.

It can, from the in-depth interviews, be concluded that bunkering operations have no influence on port choice and that bunkering is optimized on a chosen route/loop and operation (speed and loading condition) of the ship. The decision maker on the bunkering operation only deals with that aspect and does not take other aspects into account.

Sometimes, during the interviews, the respondents commented on other issues which are interesting considering bunkering of a vessel.

One shipping company said that they face reliability issues only in three ports that they are calling at: Piraeus, Malta and Antwerp. Singapore turns out to have the bestestablished bunkering standards (see also Tan 2014). The case is that the bunkering companies do not agree to the flow meter readings that are on board the ship, therefore the shipping companies do not trust that the correct quantity is supplied. At the same time, it was noted that there are no fuel quality issues at these ports. In relation to this, it was mentioned, that if the same bunker price were offered in Hamburg and Antwerp, the bunkering would be done in Hamburg because of higher trust level.

The shipping companies mention that they have a certain degree of influence on the trust factor. The use of fuel flow meters and bunker surveyors are mentioned as the main methods for ensuring that the correct quality and quantity of fuel is supplied (see also Viswa Lab 2014; Hee 2014; Liew 2014; Neo 2014).

The issue of residues of chemicals that should not be in the bunkers was raised during the interviews. The respondents from the shipping companies confirmed

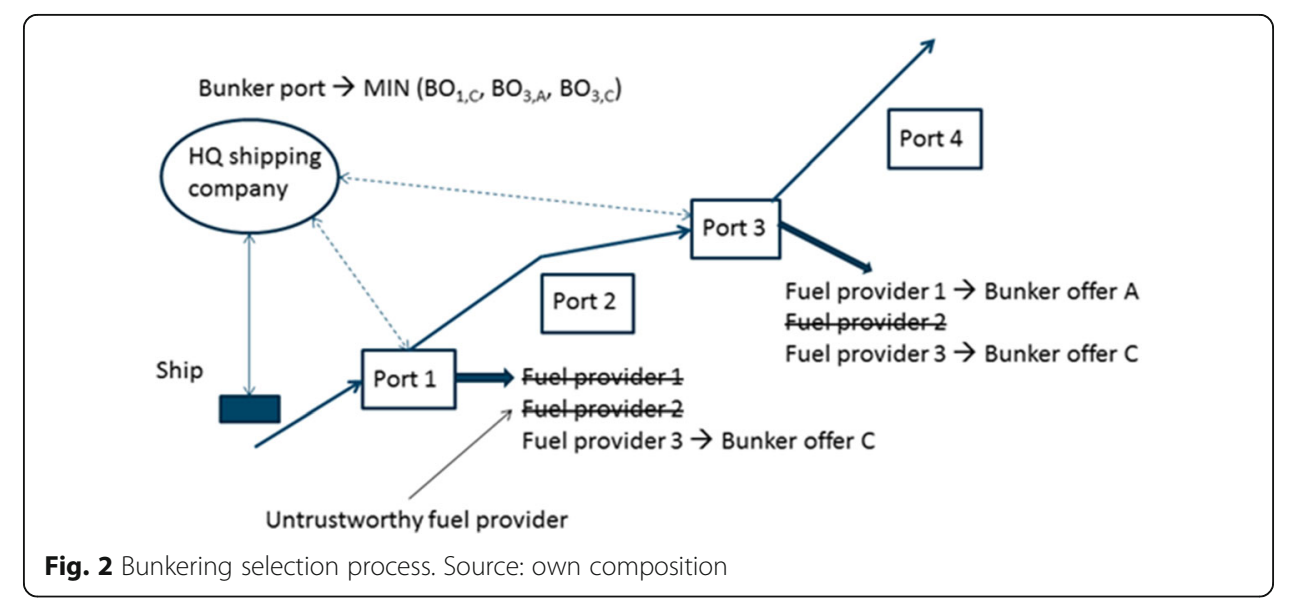


that they are aware of the problem in general, but all the respondents said that, although the presence of those residues is suspected, this is not an important issue in bunkering.

\section{Discrete choice results}

When running the model, choice parameter estimates are produced. The model was run based on a data set of five respondents who had 12 different choice sets. There are 120 unique observations. After the first model run, it was concluded that price was almost linear. Therefore, we have fitted a new model with less degrees of freedom which increased the significance of the model. The final results can be seen in Fig. 3.

The effect likelihood ratio tests show the importance of each attribute as measured by $-\log (p$-value of the LR test) and each bar represents this value relative to the value of the most important attribute. It can be seen that when the bunkering choice is made, the most important attribute is the price of fuel (linear parameter). The quality of fuel provision (defined as the trust that the correct quality and quantity of fuel is bunkered) is the second most important element. The other costs related to calling at a port and the market fit with the location of the port are significant, but their influence is less. Other attributes, like port congestion, which are still significant, and administrative attractiveness of the port do not seem to be important in the bunkering choice for the shipping companies. These parameters are more related to the port selection process. As mentioned before, the bunkering strategy is a sub-optimization of the total vessel sailing optimization that aims to minimise the total cost of ship operation.

\section{Conclusion}

The purpose of this research was to investigate the determinants of the bunkering choice of the shipping companies.

To that purpose, a methodology based on choice modeling was developed and used. This involved interviewing shipping companies from various shipping sectors. During the interviews, some important qualitative results were obtained by asking some introductory questions. The interviewees also participated in a discrete choice experiment. It is an experiment where the respondent was asked to pick the best of two presented alternatives several times. This is designed using statistical methods to measure the strength of preferences of shipping companies towards different bunkering-related characteristics of a port.

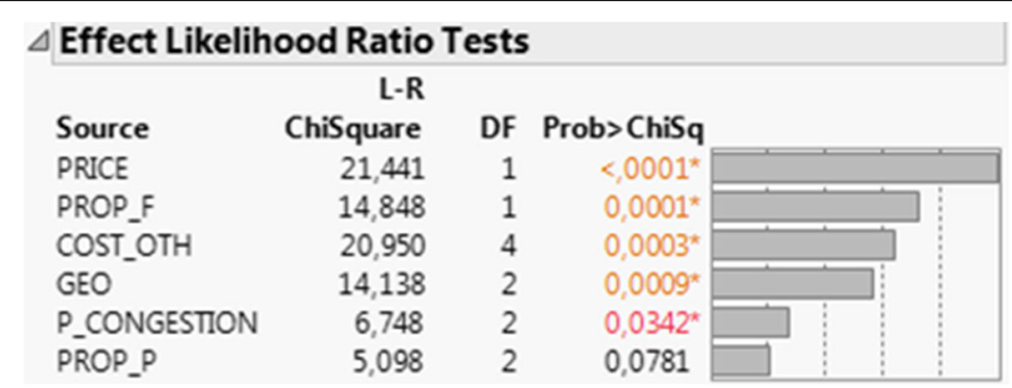

Fig. 3 Choice model parameter estimates and effect likelihood. Source: own composition 
The research allows understanding by whom and how the bunkering decisions are made. It also allows determining the most important attributes of the bunkering choice. It turns out that the price of fuel and the trust that the correct quality and quantity of fuel is bunkered are the most important determinants of the bunkering choice. The other determinants which are related to the other costs during a port call and the market fit with the location of the port were of less importance. This confirms the results of other studies on bunkering choice determinants.

The interviews confirm the above observations, and stress that in relation to fuel quantity, especially fuel availability is important. Equally, it is indicated that bunkering is always a derived activity of a port call as planned in a loop, and no other port will be called at just for bunkering.

With respect to the literature, it can be concluded that the findings of our research confirm that the bunker strategy is indeed a sub-optimization. Bunkering operations have no influence on port choice and bunkering is optimized on a chosen route/loop and operation (speed and loading condition) of the ship. However, a contradictory observation is that the bunker prices are subject to negotiations and are not fixed (only if bunkering service contracts are used). This is due to the fact that, at least for the case of North-Western Europe, there are multiple bunker providers per port which will make that there is a sort of competition. The competition between the different bunker providers will not only be on price but also on the level of trustworthiness.

The attribute of "trust", in terms of correct fuel quantity and fuel quality, is an important contribution of this research. If shipping companies do not trust a fuel supplier, they will never take bunker fuel from such companies. So, providing the correct fuel quality and the correct quantity are very important, not only for the fuel providers (for their business) but also for port authorities. If the perception is being formed that, due to a certain fuel provider, in a port the bunker cannot be trusted, then that port might find at risk all of its bunkering operations.

The results of this study can be used by port authorities, but are also important to bunkering operators. The obtained knowledge enables the port and bunkering operators to improve their competitive position in ship bunkering. This can be done by designing appropriate instruments or business strategies to target the most important attributes in bunkering choice and improve the competitive position in the ship bunkering market.

\section{Endnotes}

${ }^{1}$ JMP software package is chosen, because it incorporates a module that is specifically designed for the discrete choice experiment, and has powerful and interactive data visualization (http://www.jmp.com).

${ }^{2}$ McFadden (1974) 
Competing interests

The authors declare that they have no competing interests.

\section{Publisher's Note}

Springer Nature remains neutral with regard to jurisdictional claims in published maps and institutional affiliations.

\section{Author details}

${ }^{1}$ International Transport Forum at the OECD, 2 rue André Pascal, F-75775 Paris, France. ${ }^{2}$ Department of Transport and Regional Economics, University of Antwerp, Prinsstraat 13, B-2000 Antwerp, Belgium.

Received: 15 May 2017 Accepted: 12 December 2017

Published online: 29 December 2017

\section{References}

Acosta M, Coronado D, Del Mar Cerban M (2011) Bunkering competition and competitiveness at the ports of the Gibraltar Strait. J Transp Geogr 19:911-916

Aronietis R, Sys C, van Hassel E, Vanelslander T (2016) Forecasting port-level demand for LNG as a ship fuel: the case of the port of Antwerp. J Shipping Trade. doi: 10.1186/s41072-016-0007-1

Bech M, Kjaer T, Lauridsen J (2011) Does the number of choice sets matter? Results from a web survey applying a discrete choice experiment. Health Econ 20:273-286. doi: 10.1002/hec.1587

Ghosh S, Lee LH, Ng SH (2015) Bunkering decisions for a shipping liner in an uncertain environment with service contract. Eur J Oper Res 244(2015):792-802

Hee S. (2014) Proposed standard for the new application of mass flow metering to bunkering. Presentation at the 2014 SIBCON conference, Singapore

Liew T (2014) Metrology for bunkering - mass flow metering. Presentation at the 2014 SIBCON conference, Singapore McFadden D (1974) Conditional logit analysis of qualitative choice behavior, Zarembka P., Frontiers in econometrics. Academic Press, New York, pp 105-142

Neo S (2014) Mass flow metering. Presentation at the 2014 SIBCON conference, Singapore

Sys C, Vanelslander T, Adriaenssens M, Van Rillaer I (2015) International emission regulation in sea transport: economic feasibility and impacts. Transportation research part D, accepted for publication

Tan, S (2014) Overview of Standards \& Conformance Infrastructure to support bunkering industry. Presentation at the 2014 SIBCON conference, Singapore

Viswa Lab (2014) Bunker surveys: prevention is better than cure. Presentation at the 2014 SIBCON conference, Singapore

Wang Y, Yeo G, Ng AKY (2014) Choosing optimal bunkering ports for liner shipping companies: a hybrid fuzzy-DelphiTOPSIS approach. Transp Policy 35(2014):358-365. http://www.sciencedirect.com/science/article/pii/ S0967070X14000961.

Yao Z, Ng SH, Lee LH (2012) A study on bunker fuel management for the shipping liner services. Comput Oper Res 39(2012):1160-1172

\section{Submit your manuscript to a SpringerOpen ${ }^{\circ}$ journal and benefit from:}

- Convenient online submission

- Rigorous peer review

- Open access: articles freely available online

- High visibility within the field

- Retaining the copyright to your article 